\title{
Baerveldt or Ahmed glaucoma valve implantation with pars plana tube insertion in Japanese eyes with neovascular glaucoma: I-year outcomes
}

This article was published in the following Dove Press journal:

Clinical Ophthalmology

\section{Masayo Suda \\ Hideo Nakanishi \\ Tadamichi Akagi \\ Tomoaki Murakami \\ Kiyoshi Suzuma \\ Kenji Suda \\ Takanori Kameda \\ Satoshi Morooka \\ Hanako Ohashi Ikeda \\ Akitaka Tsujikawa \\ Department of Ophthalmology and Visual Sciences, Kyoto University \\ Graduate School of Medicine, \\ Sakyo-ku, Kyoto 606-8507, Japan}

Correspondence: Hideo Nakanishi Department of Ophthalmology and Visual Sciences, Kyoto University Graduate School of Medicine, Shogoin Kawaharacho 54, Sakyo-ku, Kyoto 606-8507, Japan Tel $+8 I 7575 I 3248$

Fax +8I 757520933

Email hideon@kuhp.kyoto-u.ac.jp
Purpose: To describe the 1-year surgical outcomes of both Baerveldt glaucoma implant (BGI) and the Ahmed glaucoma valve (AGV) implant with pars plana tube insertion in Japanese eyes with neovascular glaucoma (NVG).

Patients and methods: This was a retrospective study of 21 eyes of 18 patients who had undergone BGI (10 eyes) or AGV (11 eyes) implantation. The 1-year surgical outcomes in the two groups were compared. Surgical success was defined as an intraocular pressure (IOP) of 6-21 mmHg (criterion A) or 6-18 $\mathrm{mmHg}$ (criterion B) with $>20 \%$ reduction regardless of the use of antiglaucoma medications.

Results: The mean preoperative IOP was $33.9 \pm 6.6 \mathrm{mmHg}$ in the BGI group and $30.9 \pm 5.3 \mathrm{mmHg}$ in the AGV group $(P=0.31)$. The IOP at 1 -year was lower in the BGI group at $10.3 \pm 5.9 \mathrm{mmHg}$ than in the AGV group at $14.8 \pm 3.3 \mathrm{mmHg}(P=0.044)$. The mean number of glaucoma medications at 1 year was $1.0 \pm 1.3$ in the BGI group and $1.4 \pm 1.4$ in the AGV group $(P=0.57)$. The incidence of postoperative complications during the 1-year follow-up was not statistically different between the two groups; however, one eye in the BGI group lost light perception after additional surgery for Hoffman elbow exposure. The 1-year success rates of the BGI group was $60.0 \%$ and that in the $\mathrm{AGV}$ group was $90.9 \%$ based on criterion $\mathrm{A}(P=0.095)$, and $50.0 \%$ and $81.8 \%$ based on criterion B $(P=0.074)$.

Conclusions: Significant reductions of the IOP and number of glaucoma medications were achieved at 1 year after both types of implants in Japanese eyes with NVG.

Keywords: neovascular glaucoma, Baerveldt, Ahmed, glaucoma drainage device, pars plana tube insertion

\section{Introduction}

Neovascular glaucoma (NVG) is a major type of refractory glaucoma attributable to severe ocular ischemic diseases, such as proliferative diabetic retinopathy (PDR) and ischemic central retinal vein occlusion. ${ }^{1,2}$ Eyes with NVG have been treated by panretinal photocoagulation (PRP) or intravitreal injection of anti-vascular endothelial growth factor (aVEGF) agents to reduce the underlying ocular ischemia and angiogenic factors. Their therapeutic effectiveness has been reported; $3^{3-5}$ however, sufficient and sustained intraocular pressure (IOP) control was often not achieved by these procedures and additional surgical interventions were required. Trabeculectomy with mitomycin $\mathrm{C}$ (MMC) and glaucoma drainage devices (GDDs) are the two major surgical procedures used to reduce the IOP in eyes with NVG. ${ }^{1-3,5}$

In some cases of NVG, pars plana vitrectomy (PPV) is indicated to treat the underlying vitreoretinal disease. However, an earlier study showed that a prior vitrectomy was 
one of the factors associated with the failure of trabeculectomy for Japanese eyes with NVG. ${ }^{6}$ However, the implantation of GDDs with pars plana tube insertion for prior or simultaneous vitrectomized eyes with NVG has been reported to be efficacious. $^{7-13}$

In Japan, two types of GDDs, the Baerveldt glaucoma implant (BGI) and the Ahmed glaucoma valve (AGV), have been approved for clinical use. In both types, the pars plana tube insertion should be beneficial even in Japanese eyes with prior or simultaneous vitrectomy. However, ethnic and racial differences have been reported to be associated with the glaucoma surgical outcomes, ${ }^{14-22}$ and complications after trabeculectomy with MMC are more common in Japanese eyes than in Caucasian eyes. ${ }^{15}$ This suggested that the surgical outcomes of GDDs with pars plana tube insertion in Japanese individuals could be different from that of other ethnicities. To the best of our knowledge, there have been only a few studies published in English on the outcomes of GDD implantation with pars plana tube insertion in Japanese patients. ${ }^{23-26}$

Thus, the purpose of this study was to determine the 1-year outcomes of the implantation of BGI or AGV with pars plana tube insertion in Japanese eyes with NVG.

\section{Patients and methods}

This was a retrospective, hospital-based, single-center case series. A written informed consent form was signed by each of the patient for the original surgery. The procedures used were approved by the Institutional Review Board and Ethics Committee of Kyoto University Graduate School of Medicine, and they adhered to the tenets of the Declaration of Helsinki. We informed the patients about the retrospective medical chart review. A formal written informed consent was not required by the Institutional Review Board and Ethics Committee of Kyoto University Graduate School of Medicine for each patient for the retrospective examination and publication of their medical data. The personal information of the studied subjects was anonymized in this study. This study involved no more than minimal risk to the patients, and the waiver of signed informed consent form will not adversely affect the rights and welfare of the patients.

\section{Patients}

We reviewed the medical records of 24 eyes of 20 consecutive Japanese patients with NVG who had undergone BGI or AGV implantation at the Kyoto University Hospital between August 2012 and October 2016. Eyes were diagnosed as having NVG by glaucoma specialists by the presence of an IOP $\geq 22 \mathrm{mmHg}$ and with neovascularization of the iris and/or anterior chamber (AC) angle. A glaucomatous optic neuropathy was not needed for the diagnosis.

Among the 24 eyes, only 1 had undergone a GDD implantation with $\mathrm{AC}$ tube insertion, and that eye was excluded. Eyes with a prior history of ocular surgeries were not excluded. However, there was an eye that had undergone an explantation of a dislocated intraocular lens (IOL), and another eye that had undergone scleral suture fixation of a posterior chamber IOL for an aphakic correction simultaneously with the GDD implantation surgery. These two eyes were excluded because the extra procedures could influence the postoperative IOPs. In the end, 21 eyes of 18 patients were studied. All of the studied eyes had undergone PRP before the GDD surgery.

\section{Surgical procedures}

In our institution, the BGI with a Hoffman elbow (model BG-102-350) with a $350 \mathrm{~mm}^{2}$ area plate was used with the pars plana tube insertion for eyes with NVG until April 2015. From May 2015, the GDD used for such patients was switched to the AGV device (model FP7) with a $184 \mathrm{~mm}^{2}$ area plate without a pars plana clip. The AGV with pars plana clip had not been approved for clinical use in Japan at the time of this study. The same basic surgical procedures were used to implant these two devices in all of the patients.

After topical anesthesia and sub-Tenon anesthesia, a fornix-based flap of the conjunctiva and Tenon capsule was created by limbal peritomy. For non-vitrectomized eyes, a thorough PPV with the creation of a posterior vitreous detachment was performed before the tube insertion to prevent postoperative tube occlusion by residual vitreous. The BGI or $\mathrm{AGV}$ plate was placed $\geq 9 \mathrm{~mm}$ posterior to the limbus in the superotemporal or inferotemporal quadrant between the rectus muscles and secured with 9-0 nylon sutures. The tube was inserted into the vitreous cavity through the pars plana with a 23-gage tract located $3.5 \mathrm{~mm}$ posterior to the limbus.

For the BGI cases, the tubes were tied off by two 8-0 vicryl ligatures with one or two relieving Sherwood slits to occlude the tube temporally to prevent postoperative hypotony. No intraluminal tube stent was used in all cases. ${ }^{27}$ The tube was then secured to the sclera with 10-0 nylon sutures and covered by a patch graft. Initially, we used an autologous $6 \times 6 \mathrm{~mm}^{2}$ rectangular, limbal-based half-thickness scleral flap to cover the tube and its entry site, but in April 2014, we switched to the use of human donor sclera for the 
patch graft. ${ }^{28,29}$ The donor scleral tissues were obtained from an Eye bank of the Health Research Foundation in Kyoto, Japan. An adjunctive antimetabolite, eg, MMC, was not used at any time.

All of the patients received topical antibiotics for 1-3 months and topical corticosteroids for 3-6 months after the surgery. None of the patient received systemic antibiotics or corticosteroids. The postoperative initiation of glaucoma medications and digital massage were done during the hypertensive phase, ie, IOP $>21 \mathrm{mmHg}$ during the first 3 or 6 months after the surgeries. These were performed at the doctor's discretion. Topical aqueous suppressant after the GDD implantation to prevent the hypertensive phase was not used. ${ }^{30}$

\section{Data collection}

The data collected from the medical records included the age at the time of surgery, sex, preoperative lens status (phakic or pseudophakic), preoperative peripheral anterior synechia (PAS) evaluated by gonioscopy, etiology of the NVG, history of intraocular surgery or laser treatments, preoperative best-corrected visual acuity (BCVA), IOP, preoperative glaucoma medications, surgical procedures such as BGI or AGV implantation, intra- and postoperative complications, postoperative IOPs, and number of postoperative glaucoma medications. The BCVA was measured with a Landolt chart, and the decimal values were converted to the logarithm of the minimal angle of resolution (logMAR) units for statistical analyses. A vision of counting fingers, hand motion (HM), light perception (LP), and no light perception were defined as 2.0, 2.9, 3.2, and 3.5 $\log$ MAR units or decimal values of $1 / 100,1 / 800,1 / 1,600$, and $1 / 3,200$, respectively. ${ }^{31}$

The eyes were divided into the BGI group and the AGV group based on the type of GDD implanted. The choice of the GDDs was time dependent; BGI with Hoffman elbow (model BG-102-350) were used until April 2015, and AGV was used from May 2015. The same surgical indications criteria were applied for the use of the GDDs.

The efficacy of pars plana GDD tube insertion for NVG was based on the pre- and postoperative IOPs and the number of glaucoma medications. The preoperative IOPs and number of glaucoma medications were recorded as the mean of two consecutive outpatient values just before surgery. The postoperative IOP was measured on days $1,7,14,30,60,90$, and every 90 days thereafter. The postoperative number of glaucoma medications was taken to be the number on day $14,30,60,90$, and every 90 days thereafter.

\section{Statistical analyses}

The continuous variables are expressed as the means \pm SDs. For future meta-analyses, we presented the mean $\mathrm{SD}$ values and parametric test results.

The significance of the differences in the demographic features between the AGV group and the BGI group was determined by the Fisher's exact test for dichotomous data or by the unpaired $t$-tests for continuous data. The rates of postoperative complications were also compared between the two groups by Fisher's exact tests. Paired $t$-tests were used to determine the significance of the differences in the IOPs and number of glaucoma medications at two time points.

Comparisons of surgical success rates between the groups were determined by Kaplan-Meier survival analysis. The surgical success was defined as an IOP $\leq 21 \mathrm{mmHg}$ (criterion $\mathrm{A}$ ) or $\leq 18 \mathrm{mmHg}$ (criterion B) with a lower limit of $6 \mathrm{mmHg}$ regardless of any antiglaucoma medication use. A sustained IOP out of the success range or a $\leq 20 \%$ reduction from the preoperative IOP at two consecutive time points was considered a surgical failure at the first time point. For the evaluation of the surgical success, the postoperative IOPs at days 90,180 , and then every 90 days thereafter were evaluated. Eyes that required additional surgery for postoperative uncontrolled IOP elevation, hypotonic complications, and tube/implant exposure were also defined as failures. The success rates based on criteria A and B were compared between the AGV and BGI groups by log-rank tests.

Univariate Cox proportional hazard regression analyses were performed to evaluate the influence of each pre- and intraoperative factors, eg, age, sex, preoperative IOP, and type of GDD, on the surgical success rates based on criteria $\mathrm{A}$ and $\mathrm{B}$. The factors with a $P$-value $<0.2$ in the univariate analysis were further analyzed with multivariate Cox proportional hazard regression analysis to determine the independent association of each factor after adjustment for these confounders.

The level of statistical significance was set at $P<0.05$. Patients who underwent additional surgeries for the surgical failure were removed from the analysis after the time of reoperation. The statistical analyses were performed with software R (https://cran.r-project.org/index.html).

\section{Results}

The preoperative demographics of the 21 eyes of 18 patients are shown in Table 1. Among the 21 eyes, 10 eyes ( 9 patients) had the BGI (model BG-102-350 with Hoffman elbow) 
Table I Demographics of the study subjects and eyes

\begin{tabular}{|c|c|c|c|}
\hline Group & BGI & AGV & $P$-value ${ }^{a}$ \\
\hline Number of eyes & 10 eyes ( 9 patients) & II eyes ( 9 patients) & \\
\hline Date of surgery & August 20I2-April 2015 & May 2015-October 2016 & \\
\hline Follow-up period, months & $30.8 \pm 7.6$ & $15.3 \pm 3.7$ & $7.9 \times 10^{-6}$ \\
\hline Age at surgery, years & $57.1 \pm 14.4$ & $68.9 \pm 8.5$ & 0.032 \\
\hline \multicolumn{4}{|l|}{ Gender, eyes (\%) } \\
\hline Men & $5(50.0)$ & $9(81.8)$ & 0.18 \\
\hline Women & $5(50.0)$ & $2(18.2)$ & \\
\hline Preoperative IOP, $\mathrm{mmHg}$ & $33.9 \pm 6.6$ & $30.9 \pm 5.3$ & 0.26 \\
\hline Preoperative number of glaucoma medication & $3.2 \pm 1.4$ & $4.0 \pm 1.0$ & 0.17 \\
\hline Preoperative BCVA (logMAR) & $1.73 \pm 1.03$ & $1.00 \pm 1.10$ & 0.13 \\
\hline \multicolumn{4}{|l|}{ Preoperative lens status, number (\%) } \\
\hline Pseudophakia & $9(90.0)$ & II (100.0) & 0.48 \\
\hline Aphakia & $I(10.0)$ & $0(0.0)$ & \\
\hline Phakia & $0(0.0)$ & $0(0.0)$ & \\
\hline \multicolumn{4}{|l|}{ Gonioscopic PAS index, number (\%) } \\
\hline $0 \%$ (open angle) & $I(10.0)$ & $4(36.4)$ & 0.42 \\
\hline $1 \%-50 \%$ & $2(20.0)$ & $2(18.2)$ & \\
\hline $51 \%-100 \%$ & $7(70.0)$ & $5(45.5)$ & \\
\hline \multicolumn{4}{|l|}{ Etiology of neovascular glaucoma, number (\%) } \\
\hline PDR & $8(80.0)$ & $9(81.8)$ & 0.23 \\
\hline Central retinal vein occlusion & $0(0.0)$ & $2(18.2)$ & \\
\hline Ocular ischemic syndrome & $2(20.0)$ & $0(0.0)$ & \\
\hline History of previous PRP, number (\%) & $10(100.0)$ & II (I00.0) & 1.00 \\
\hline \multicolumn{4}{|l|}{ Previous glaucoma surgery, number (\%) } \\
\hline No & $7(70.0)$ & $7(63.6)$ & 1.00 \\
\hline I time & $2(20.0)$ & $3(27.3)$ & \\
\hline 3 times & $I(10.0)$ & $\mathrm{I}(9.1)$ & \\
\hline \multicolumn{4}{|l|}{ Previous vitrectomy surgery, number (\%) } \\
\hline No & $2(20.0)$ & $0(0.0)$ & 0.22 \\
\hline I time & $3(30.0)$ & $7(63.6)$ & \\
\hline 2 times & $4(40.0)$ & $4(36.4)$ & \\
\hline 4 times & $I(10.0)$ & $0(0.0)$ & \\
\hline Preoperative aVEGF injection within I month, number (\%) & $3(30.0)$ & $7(63.6)$ & 0.20 \\
\hline \multicolumn{4}{|l|}{ Location of plate implantation, number (\%) } \\
\hline Superotemporal quadrant & $8(80.0)$ & $9(81.8)$ & 1.00 \\
\hline Inferotemporal quadrant & $2(20.0)$ & $2(18.2)$ & \\
\hline \multicolumn{4}{|l|}{ Patch graft, number (\%) } \\
\hline Autologous scleral flap & $5(50.0)$ & $0(0.0)$ & 0.012 \\
\hline Donor scleral graft & $5(50.0)$ & II (I00.0) & \\
\hline
\end{tabular}

Notes: Unpaired $t$-test for continuous variables, Fisher's exact test for dichotomous variables. Continuous variables were expressed as mean \pm SD. Nominal $P$-values without multiple testing corrections are shown.

Abbreviations: AGV, Ahmed glaucoma valve; BCVA, best corrected visual acuity; BGI, Baerveldt glaucoma implant; IOP, intraocular pressure; PAS, peripheral anterior synechia; PRP, panretinal photocoagulation; aVEGF, anti-vascular endothelial growth factor; logMAR, logarithm of the minimal angle of resolution; PDR, proliferative diabetic retinopathy.

implantation and 11 eyes ( 9 patients) had the AVG (model FP7 without pars plana clip) implantation. Both had undergone pars plana tube insertion. The preoperative demographics of the BGI group were not significantly different from that of the AGV group except for the age at the time of surgery. The mean $\pm \mathrm{SD}$ of the age at the time of surgery was $57.1 \pm 14.4$ years in the BGI group and $68.9 \pm 8.5$ years in the $\mathrm{AGV}$ group $(P=0.032)$. 
Because the GDD used was completely switched from BGI to AGV in our institution in May 2015, the follow-up period was significantly longer in the BGI group than in the AGV group. In addition, the patch graft material was switched from autologous scleral flap to human donor sclera in April 2014. Therefore, both the autologous scleral flap $(50 \%)$ and donor scleral graft (50\%) were used in the BGI group, whereas only the donor scleral graft (100\%) was used in the AGV group $(P=0.012)$.

The values of the IOPs after the surgeries are shown in Table 2 for the two groups. One eye underwent additional surgery for an exposed Hoffman elbow that required an explantation of the BGI implant at 7 months after the initial GDD surgery. The data of this eye were excluded from analyses after the time of the reoperation.

The IOP was significantly and consistently reduced in both the BGI and AGV groups during the first 12 months after the surgery. The mean IOP at each time point after the surgery is shown in Figure 1. Although the IOP tended to be higher in the BGI group than in the AGV group during the first 3 months, the differences of the IOP distribution at each time point was not significant (Table 2). However, the mean IOP at 12 months after surgery was significantly lower in the BGI group
$(10.3 \pm 5.9 \mathrm{mmHg})$ than in the $\mathrm{AGV}$ group $(14.8 \pm 3.3 \mathrm{mmHg}$; $P=0.044)$, although one eye in the BGI group required a reoperation, and the data from this eye were excluded from the statistical analyses. An IOP $>21 \mathrm{mmHg}$ during the 6 months after the surgeries, ie, hypertensive phase, was observed in eight of the ten eyes $(80.0 \%)$ in the BGI group, whereas three of the eleven eyes (27.3\%) in the AGV group ( $P=0.030)$.

The time course of the mean number of glaucoma medications after the surgeries in the two groups are also shown in Table 2. The mean number of glaucoma medications in the BGI group was significantly higher than that in the $\mathrm{AGV}$ group at 14 days $(1.9 \pm 2.1$ vs $0.2 \pm 0.4$, respectively; $P=0.017)$ and at 30 days after surgery $(2.2 \pm 1.9$ vs $0.3 \pm 0.6$, respectively; $P=5.5 \times 10^{-3}$ ). The number of glaucoma medication was not significantly different between the groups thereafter (Figure 2).

No serious intraoperative complications, such as rhegmatogenous retinal detachment or suprachoroidal hemorrhage, occurred in either group. The incidence of each postoperative complication during the 12 months of follow-up tended to be higher in the BGI group than in the AGV group; however, the difference was not statistically significant (Table 3). One eye underwent additional surgery

Table 2 Mean IOP and number of glaucoma medications during I year after pars plana tube insertion of BGI or AGV for eyes with neovascular glaucoma

\begin{tabular}{|c|c|c|c|c|c|c|}
\hline \multirow[t]{2}{*}{ Category } & \multirow{2}{*}{$\begin{array}{l}\text { Postoperative } \\
\text { day }\end{array}$} & \multirow{2}{*}{$\begin{array}{l}\text { BGI ( } 10 \text { eyes) } \\
\text { Mean } \pm \text { SD }\end{array}$} & \multirow{2}{*}{$\begin{array}{l}P \text {-value }{ }^{a} \text { vs } \\
\text { preoperative }\end{array}$} & \multirow{2}{*}{$\begin{array}{l}\text { AGV (I I eyes) } \\
\text { Mean } \pm \text { SD }\end{array}$} & \multirow{2}{*}{$\begin{array}{l}P \text {-value }{ }^{a} \text { vs } \\
\text { preoperative }\end{array}$} & \multirow{2}{*}{$\begin{array}{l}\text {-value }{ }^{\mathrm{b}} \\
\text { BGI vs AGV }\end{array}$} \\
\hline & & & & & & \\
\hline \multirow[t]{10}{*}{ IOP } & Preoperative & $33.9 \pm 6.6$ & & $30.9 \pm 5.3$ & & 0.26 \\
\hline & $\mathrm{I}$ & $13.8 \pm 8.8$ & $7.6 \times 10^{-5}$ & $11.4 \pm 6.7$ & $1.3 \times 10^{-7}$ & 0.48 \\
\hline & 7 & $16.9 \pm 10.7$ & $4.2 \times 10^{-4}$ & $10.7 \pm 5.2$ & $4.3 \times 10^{-8}$ & 0.10 \\
\hline & 14 & $19.4 \pm 13.7$ & $6.9 \times 10^{-3}$ & $14.5 \pm 7.9$ & $8.1 \times 10^{-6}$ & 0.32 \\
\hline & 30 & $19.7 \pm 10.1$ & $5.5 \times 10^{-4}$ & $13.9 \pm 6.5$ & $7.5 \times 10^{-6}$ & 0.13 \\
\hline & 60 & $15.5 \pm 12.9$ & $2.3 \times 10^{-3}$ & $13.1 \pm 4.8$ & $3.8 \times 10^{-6}$ & 0.57 \\
\hline & 90 & $13.4 \pm 6.8$ & $1.4 \times 10^{-4}$ & $13.9 \pm 5.5$ & $2.4 \times 10^{-5}$ & 0.85 \\
\hline & 180 & $14.0 \pm 6.5$ & $1.7 \times 10^{-4}$ & $14.2 \pm 3.1$ & $9.9 \times 10^{-7}$ & 0.92 \\
\hline & 270 & $14.9 \pm 7.2^{c}$ & $9.2 \times 10^{-4}$ & $16.3 \pm 5.1$ & $8.0 \times 10^{-5}$ & 0.62 \\
\hline & 360 & $10.3 \pm 5.9^{c}$ & $6.8 \times 10^{-6}$ & $14.8 \pm 3.3$ & $2.1 \times 10^{-6}$ & 0.044 \\
\hline \multirow{8}{*}{$\begin{array}{l}\text { Number of } \\
\text { glaucoma } \\
\text { medication }\end{array}$} & Preoperative & $3.2 \pm 1.4$ & & $4.0 \pm 1.0$ & & 0.17 \\
\hline & 14 & $1.9 \pm 2.1$ & 0.033 & $0.2 \pm 0.4$ & $1.4 \times 10^{-6}$ & 0.017 \\
\hline & 30 & $2.2 \pm 1.9$ & 0.074 & $0.3 \pm 0.6$ & $2.1 \times 10^{-7}$ & $5.5 \times 10^{-3}$ \\
\hline & 60 & $1.7 \pm 1.8$ & $9.1 \times 10^{-3}$ & $0.7 \pm 1.3$ & $1.6 \times 10^{-5}$ & 0.16 \\
\hline & 90 & $0.9 \pm 1.3$ & $2.6 \times 10^{-3}$ & $0.7 \pm 1.3$ & $1.6 \times 10^{-5}$ & 0.76 \\
\hline & 180 & $0.8 \pm 1.0$ & $3.1 \times 10^{-3}$ & $0.8 \pm 1.3$ & $1.4 \times 10^{-5}$ & 0.97 \\
\hline & 270 & $1.1 \pm 1.3^{c}$ & 0.015 & $1.0 \pm 1.4$ & $4.7 \times 10^{-5}$ & 0.86 \\
\hline & 360 & $1.0 \pm 1.3^{c}$ & 0.014 & $\mathrm{I} .4 \pm \mathrm{I} .4$ & $6.0 \times 10^{-5}$ & 0.57 \\
\hline
\end{tabular}

Notes: a Paired $t$-test. ${ }^{b} U n p a i r e d ~ t$-test. Nominal $P$-values without multiple testing corrections are shown. ${ }^{\circ}$ One eye underwent additional surgery for exposure of BGI implant 7 months after initial GDD surgery, and the eye was censored from analysis after the time of reoperation.

Abbreviations: AGV, Ahmed glaucoma valve; BGI, Baerveldt glaucoma implant; IOP, intraocular pressure; GDD, glaucoma drainage device. 


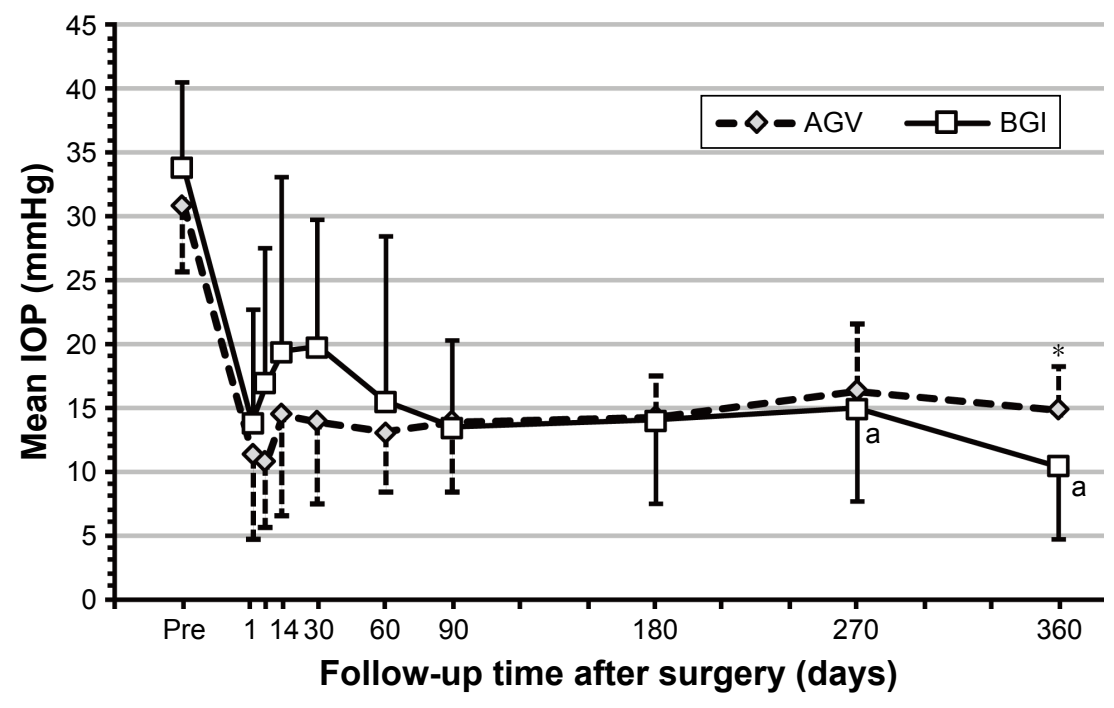

Figure I Mean IOP during I-year after pars plana tube insertion of two types of GDDs in Japanese eyes with NVG.

Notes: Error bars represent SD. $* P<0.05$. ane eye underwent additional surgery for exposure of $B G I$ implant 7 months after the initial GDD surgery, and the data of this eye were excluded from the analyses after the time of the reoperation.

Abbreviations: AGV, Ahmed glaucoma valve; BGI, Baerveldt glaucoma implant; GDDs, glaucoma drainage device; IOP, intraocular pressure; NVG, neovascular glaucoma.

to remove the BGI implant because of an exposure of Hoffman elbow 7 months after the GDD implantation surgery (Table 4). The Hoffman elbow had been covered by donor scleral graft at initial GDD surgery, but graft erosion and melting resulted in the exposure of Hoffman elbow. This eye developed a retinal detachment with choroidal detachment, ie, an anterior proliferative vitreoretinopathy, after the explantation of the BGI; however, the patient refused additional intervention. The preoperative decimal BCVA of this eye was 0.1 (20/200 Snellen units), and the eye lost LP at 10 months after the initial GDD surgery. Another eye in the AGV group also lost LP 9 months after the GDD surgery (Table 4). However, the eye had successful IOP control without any complication during the postoperative period and the preoperative BCVA of the eye was HM.

The distribution of the BCVAs before and 12 months after the GDD surgery in each group is shown in Figure 3. Statistical comparison between the pre- and postoperative corneal endothelial cell counts could not be performed because of missing data.

The 1-year success rates regardless of glaucoma medication use, ie, the qualified success rates, of the BGI group and the AGV group were $60.0 \%$ and $90.9 \%$ based on criterion $\mathrm{A}(P=0.095)$, and $50.0 \%$ and $81.8 \%$ based on criterion $\mathrm{B}(P=0.074)$, respectively (Figure 4$)$. The reasons for the surgical failure in each group are listed in Table 4.

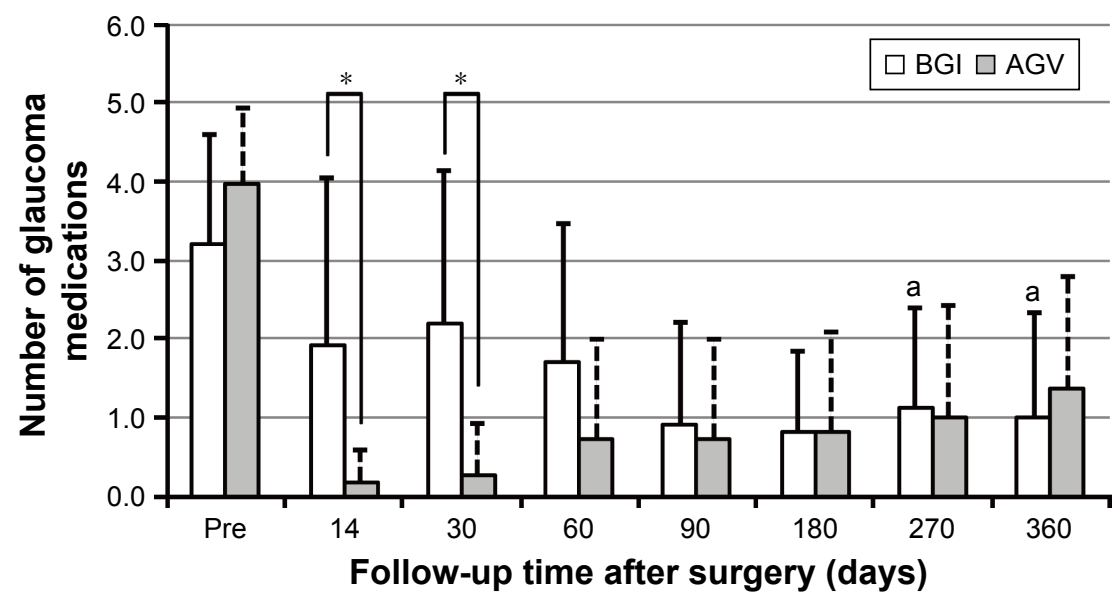

Figure 2 Mean number of glaucoma medications during I-year after pars plana tube insertion of two types of GDDs in Japanese eyes with NVG. Notes: Error bars represent SD. $* P<0.05$. ${ }^{a}$ One eye underwent additional surgery for exposure of BGI implant 7 months after the initial GDD surgery, and the data of this eye were excluded from the analysis after the time of reoperation.

Abbreviations: AGV, Ahmed glaucoma valve; BGI, Baerveldt glaucoma implant; GDD, glaucoma drainage device; NVG, neovascular glaucoma. 
Table 3 Postoperative complications during I-year after pars plana tube insertion of BGI or AGV for eyes with neovascular glaucoma

\begin{tabular}{|c|c|c|c|}
\hline & $\begin{array}{l}\text { BGI } \\
\text { ( } 10 \text { eyes) }\end{array}$ & $\begin{array}{l}\text { AGV } \\
\text { (I I eyes) }\end{array}$ & $P$-value ${ }^{a}$ \\
\hline \multicolumn{4}{|c|}{ Early complications (within I month), eyes (\%) } \\
\hline Hyphema & $3(30.0)$ & $0(0.0)$ & 0.090 \\
\hline Hypotony ( $\leq 5 \mathrm{mmHg})$ & $4(40.0)$ & $2(18.2)$ & 0.36 \\
\hline Choroidal detachment & $3(30.0)$ & I (9.I) & 0.31 \\
\hline Vitreous hemorrhage & $2(20.0)$ & I (9.1) & 0.59 \\
\hline Sum & $6(60.0)$ & $3(27.3)$ & 0.20 \\
\hline \multicolumn{4}{|c|}{ Late complications ( $1-12$ months), eyes (\%) } \\
\hline Hypotony ( $\leq 5 \mathrm{mmHg}$ ) & $3(30.0)$ & $0(0.0)$ & 0.090 \\
\hline Vitreous hemorrhage & $2(20.0)$ & $0(0.0)$ & 0.21 \\
\hline Exposure of tube/plate & $\mathrm{I}(10.0)$ & $0(0.0)$ & 0.48 \\
\hline Anterior PVR & $I(10.0)$ & $0(0.0)$ & 0.48 \\
\hline Loss of light perception & I $(10.0)$ & I (9.I) & 1.00 \\
\hline Iris bombe & $\mathrm{I}(10.0)$ & $0(0.0)$ & 0.48 \\
\hline Diplopia & $0(0.0)$ & $0(0.0)$ & 1.00 \\
\hline Corneal edema & $0(0.0)$ & $0(0.0)$ & 1.00 \\
\hline Endophthalmitis & $0(0.0)$ & $0(0.0)$ & 1.00 \\
\hline Sum & $4(40.0)$ & I (9.I) & 0.15 \\
\hline
\end{tabular}

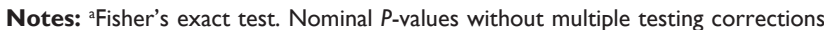
are shown.

Abbreviations: AGV, Ahmed glaucoma valve; BGl, Baerveldt glaucoma implant; PVR, proliferative vitreoretinopathy.

Univariate Cox proportional hazard regression analyses showed that the patch graft material and GDD types had $P$-values $<0.2$ based on criteria A and $\mathrm{B}$. The preoperative BCVA and the range of PAS also had $P$-values $<0.2$ based on criterion $\mathrm{A}$, whereas the preoperative number of glaucoma medications, etiology of NVG, and prior history of vitrectomy had $P$-value $<0.2$ based on criterion B (Table 5). However, none of these factors remained as significant contributing determinants for surgical success or failure based on either criterion A or B after adjustment for cofounding effect by multivariate analyses (Table 5).

\section{Discussion}

The surgical outcomes of the BGI and AGV implantations after insertion of the tube in AC for refractory glaucoma have been compared in several randomized clinical trials and meta-analyses. ${ }^{32-37}$ However, the surgical outcomes after pars plana tube insertion has been reported by case series. There have been only a few studies published with English abstracts that evaluated the surgical outcomes of pars plana tube insertion of these GDDs in Japanese patients. ${ }^{23-26}$ In our study, the implantation of both the BGI and the AGV devices with pars plana tube insertion led to significant and sustained reduction of the IOPs for at least 12 months in Japanese eyes with NVG. The number of glaucoma medications was also significantly reduced. These results agreed with the 1-year outcomes of the earlier randomized clinical trials that reported on the efficacy of these GDDs but with $\mathrm{AC}$ tube insertion for eyes with refractory glaucoma. ${ }^{38,39} \mathrm{Our}$ results suggest that pars plana tube insertion of GDDs would have similar results for Japanese eyes with NVG for at least 12 months. However, this follow-up period is relatively short, and earlier studies with longer follow-up periods showed that patients with NGV had a greater risk of surgical failure after AC tube insertion of GDD compared with controls..$^{12,40}$ Other earlier studies evaluated the outcomes of $\mathrm{AC}$ tube insertion of BGI and AGV for refractory glaucoma with a

Table 4 Reasons for treatment failure during I year after pars plana tube insertion of BGI or AGV for eyes with neovascular glaucoma

\begin{tabular}{|c|c|c|c|c|c|c|}
\hline & \multicolumn{3}{|l|}{ Criterion $\mathbf{A}^{\mathrm{a}}$} & \multicolumn{3}{|l|}{ Criterion $\mathbf{B}^{\mathbf{a}}$} \\
\hline & BGI ( 10 eyes) & AGV (I I eyes) & $P$-value ${ }^{\text {b }}$ & BGI ( 10 eyes) & AGV (I I eyes) & $P$-value ${ }^{b}$ \\
\hline \multicolumn{7}{|c|}{ Inadequate IOP control at two consecutive time points without additional surgery, eyes (\%) } \\
\hline Excess of upper limit & $I(10.0)$ & $0(0)$ & 0.48 & $2(20.0)$ & $\mathrm{I}(9.1)$ & 0.59 \\
\hline Hypotony & $2(20.0)$ & $0(0)$ & 0.21 & $2(20.0)$ & $0(0)$ & 0.21 \\
\hline \multicolumn{7}{|l|}{ Additional surgery, eyes (\%) } \\
\hline Reoperation for hypertension & $0(0.0)$ & $0(0)$ & 1.00 & $0(0.0)$ & $0(0)$ & 1.00 \\
\hline Reoperation for persistent hypotony & $0(0.0)$ & $0(0)$ & 1.00 & $0(0.0)$ & $0(0)$ & 1.00 \\
\hline Explantation of GDD for complication & $I(10.0)$ & $0(0)$ & 0.48 & $I(10.0)$ & $0(0)$ & 0.48 \\
\hline Loss of light perception, eyes (\%) & $I(10.0)$ & $\mathrm{I}(9.1)$ & 1.00 & $I(10.0)$ & $\mathrm{I}(9.1)$ & 1.00 \\
\hline Total & $4(40.0)$ & I (9.1) & 0.15 & $5(50.0)$ & $2(18.2)$ & 0.18 \\
\hline
\end{tabular}

Notes: aSurgical success was defined as an IOP of 6-21 mmHg (Criterion A) or 6-18 mmHg (Criterion B) with $<20 \%$ reduction from the preoperative IOP regardless of

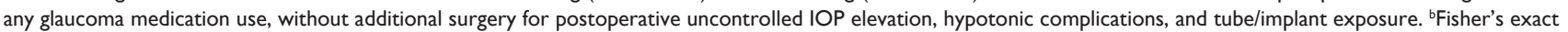
test. Nominal $P$-values without multiple testing corrections are shown.

Abbreviations: AGV, Ahmed glaucoma valve; BGI, Baerveldt glaucoma implant; GDD, glaucoma drainage device; IOP, intraocular pressure. 


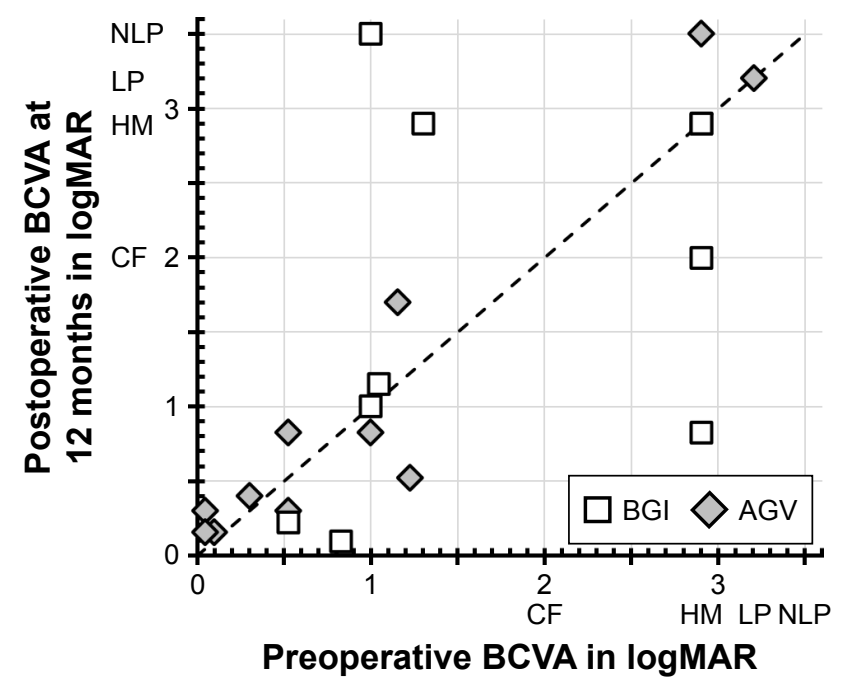

Figure 3 Scatterplot of preoperative and postoperative visual acuity in logMAR units at I year after pars plana tube insertion of two types of GDDs for Japanese eyes with NVG.

Note: A vision of CF, HM, LP, and no light perception were defined as 2.0, 2.9, 3.2, and $3.5 \log$ MAR units (equivalent for a decimal value of $1 / 100,1 / 800,1 / 1,600$, and I/3,200), respectively. ${ }^{31}$

Abbreviations: AGV, Ahmed glaucoma valve; BCVA, best-corrected visual acuity; BGI, Baerveldt glaucoma implant; CF, counting fingers; GDDs, glaucoma drainage devices; HM, hand motion; logMAR, logarithm of the minimal angle of resolution; LP, light perception; NLP, no light perception; NVG, neovascular glaucoma.

longer follow-up period and showed higher incidences of failure of the IOP control in the AGV group than the BGI group. ${ }^{34-37}$ Thus, future comparative studies with long-term follow-up times are needed.

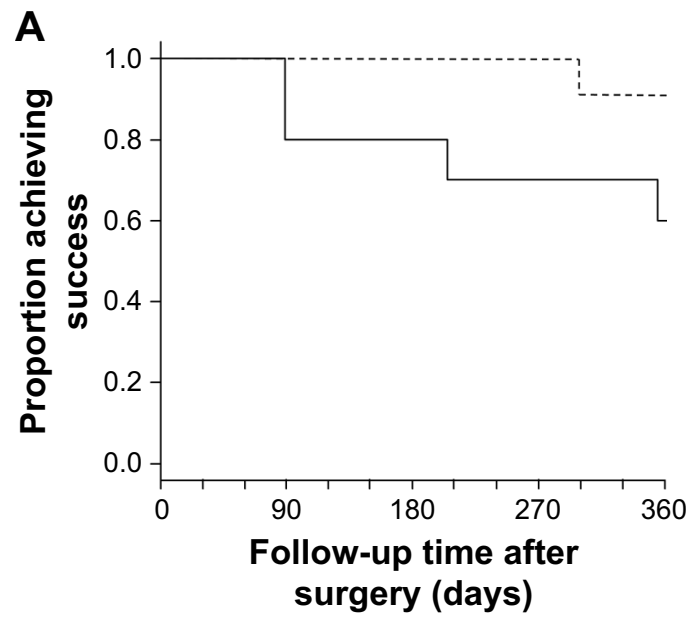

The time-course of the IOPs and the number of glaucoma medications for the two GDDs also agreed with the results of earlier randomized clinical trial studies that evaluated the outcomes of AC tube insertion for refractory glaucoma. ${ }^{38,39}$ During the 3-month postoperative period, the eyes in the BGI group tended to have higher IOPs and used a larger number of glaucoma medications, but this pattern reversed after 3 postoperative months (Figures 1 and 2). For the BGI cases in our study, the tube was tied off with Sherwood slits, and an intraluminal tube stent was not used. This probably accounts for the higher IOPs and greater number of medications during the first 3 months in the BGI group.

The average IOP at 12 months after the surgery was significantly lower in the BGI group. On the other hand, the incidence of postoperative complications tended to be higher in the BGI group than in the AGV group (Tables 3 and 4). These findings also agree with the results of earlier randomized clinical trials. ${ }^{38,39}$ One eye in the BGI group developed an exposure of the Hoffman elbow, and the BGI had to be surgically removed. The vision in this eye eventually lost all LP because of retinal and choroidal detachments. This supports the results of earlier studies that reported that NVG was a risk factor for postoperative GDD exposure, ${ }^{16}$ and surgeons need to determine the type of GDD based on the targeted IOP with attention for the incidence and severity of the complications. ${ }^{36,37}$

B

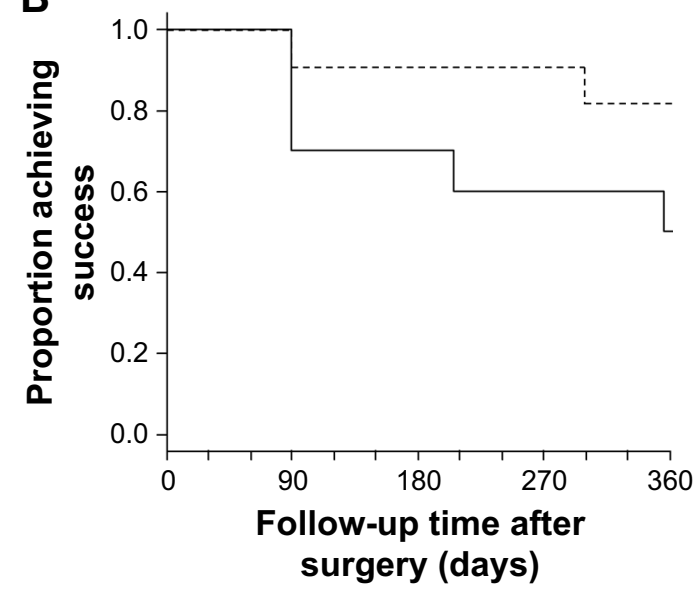

\begin{tabular}{lllll}
\multicolumn{2}{l}{ Number at risk } \\
BGI 10 & 10 & 7 & 6 & 5 \\
AGV 11 & 11 & 10 & 10 & 9
\end{tabular}

BGI ---- AGV

Figure 4 Kaplan-Meier survival curves of surgical success after pars plana tube insertion of two types of GDDs in Japanese eyes with NVG. Notes: (A) Survival analysis curve based on criterion A, defined as an IOP of $6-21 \mathrm{mmHg}$ with a $>20 \%$ reduction from the preoperative IOP regardless of any antiglaucoma medication use. Additional surgery for postoperative uncontrolled IOP elevation, hypotonic complications, and tube/implant exposure were defined as a failure. (B) Survival analysis curve based on criterion $\mathrm{B}$, defined as an IOP of $6-18 \mathrm{mmHg}$ with a $>20 \%$ reduction from the preoperative IOP regardless of any antiglaucoma medication use. Additional surgery for postoperative uncontrolled IOP elevation, hypotonic complications, and tube/implant exposure were defined as a failure.

Abbreviations: AGV, Ahmed glaucoma valve; BGI, Baerveldt glaucoma implant; GDDs, glaucoma drainage device; IOP, intraocular pressure; NVG, neovascular glaucoma. 


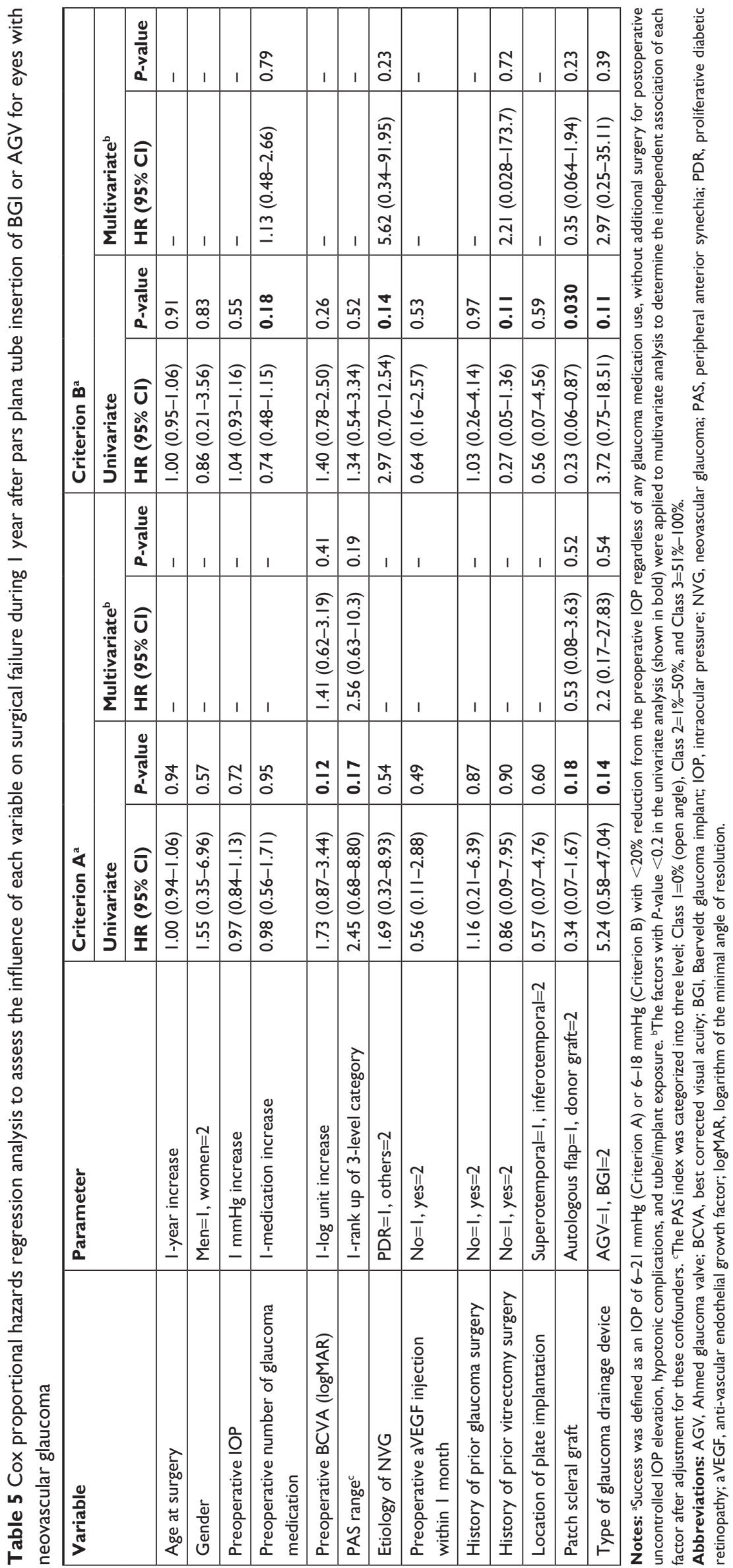


Prior or simultaneous extensive PPV is needed for pars plana tube insertion of the GDDs. This is a disadvantage for eyes with primary open angle glaucoma (POAG) because PPV is usually not indicated for eyes with POAG. On the other hand, PPV is often indicated in eyes with NVG to treat the underlying vitreoretinal diseases. In this study, 19 of the 21 eyes $(90.5 \%)$ had undergone vitrectomy prior to the GDD surgeries; 17 eyes for a combination of tractional retinal detachment, vitreous hemorrhage, and macular edema attributable to PDR, and the other two eyes underwent PPV for vitreous hemorrhage or macular edema attributable to a central retinal vein occlusion. The remaining 2 of the 21 eyes $(9.5 \%)$ had simultaneous PPV and GDD implantation because of the ocular ischemic syndrome and moderate cataract. The simultaneous PPV and cataract surgery enabled us to perform the complete PRP by adding endolaser photocoagulation of the peripheral retina. Thus, GDD with pars plana tube insertion after or simultaneous with the PPV would be more suitable. However, we could not perform a comparative study between pars plana vs AC tube insertion because only one eye with NVG underwent AC tube insertion during the study period in our institution.

The major limitation of this study was the small sample size and short follow-up period. For meta-analysis expected in the future, we presented the mean \pm SD values and parametric test results. Log-rank analyses did not show significant differences in the surgical success rates between the BGI and AGV groups. Prognostic factor analyses using Cox proportional hazard regression model did not detect any significant contributing determinants for surgical success or failure after adjustment for cofounding effects. These negative results were most likely due to the low statistical power. Several factors, eg, adjunctive aVEGF therapy, ${ }^{41,42}$ have been reported as contributing determinants for surgical success of AC tube insertion of GDD, and it is important to evaluate their contribution to surgical success of pars plana tube insertion of GDD. However, we cannot make any definitive statements on these evaluations.

Another limitation is the retrospective design. It is reasonable that pars plana tube insertion of GDD would have less chance of corneal endothelial cell decrease than AC tube insertion. ${ }^{43}$ However, there were cases with missing data of corneal endothelial cell density in this study. We could not evaluate the changes of the corneal endothelial cell counts and its time course accurately after the pars plana tube insertion of GDD.

Another limitation is a selection bias. During the study period, all of the prior-vitrectomized eyes with NVG underwent pars plana tube insertion of GDD in our institution. On the other hand, the selection of the surgical procedures for non-vitrectomized eyes with NVG was surgeon dependent. Two eyes that underwent simultaneous PPV and pars plana tube insertion of GDD were included in this study. On the other hand, the same surgeons performed trabeculectomy with MMC for two non-vitrectomized eyes with NVG, ExPRESS implantation with MMC for 5 non-vitrectomized eyes with NVG, and cyclocryopexy for three non-vitrectomized eyes with NVG during the studied period. Matching of the demographics of the studied eyes between the BGI and AGV groups was difficult, and the mean age of the two groups was significantly different. To overcome these limitations, future prospective studies with larger sample sizes and strict protocols are needed.

\section{Conclusion}

In conclusion, the results of this study showed significant reductions of the IOP and number of glaucoma medications 1 year after implantation for both GDDs, ie, BGI and AGV with pars plana tube insertion in Japanese eyes with NVG. These results are comparable to those of the 1-year outcomes of the implantation of GDDs with AC tube insertions in earlier randomized clinical trials for refractory glaucoma in Caucasian eyes. ${ }^{38,39}$ However, 1 of the 21 studied eyes with BGI implantation lost LP after a severe postoperative complication.

\section{Acknowledgment}

This study was partly supported by grants from Grant-in-Aid for Scientific Research (25462713) from the Japan Society for the Promotion of Science (JSPS).

\section{Disclosure}

The authors report no conflicts of interest in this work.

\section{References}

1. Hayreh SS. Neovascular glaucoma. Prog Retin Eye Res. 2007;26(5): 470-485.

2. Rodrigues GB, Abe RY, Zangalli C, et al. Neovascular glaucoma: a review. Int $J$ Retina Vitreous. 2016;2(1):26.

3. Sivak-Callcott JA, O'Day DM, Gass JD, Tsai JC. Evidence-based recommendations for the diagnosis and treatment of neovascular glaucoma. Ophthalmology. 2001;108(10):1767-1776.

4. Simha A, Braganza A, Abraham L, Samuel P, Lindsley K. Anti-vascular endothelial growth factor for neovascular glaucoma. Cochrane Database Syst Rev. 2013;(10):CD007920.

5. Olmos LC, Lee RK. Medical and surgical treatment of neovascular glaucoma. Int Ophthalmol Clin. 2011;51(3):27-36.

6. Takihara $\mathrm{Y}$, Inatani M, Fukushima M, Iwao K, Iwao M, Tanihara H. Trabeculectomy with mitomycin $\mathrm{C}$ for neovascular glaucoma: prognostic factors for surgical failure. Am J Ophthalmol. 2009;147(5):912-918.

7. Jeong HS, Nam DH, Paik HJ, Lee DY. Pars plana Ahmed implantation combined with 23-gauge vitrectomy for refractory neovascular glaucoma in diabetic retinopathy. Korean J Ophthalmol. 2012;26(2):92-96.

8. Luttrull JK, Avery RL. Pars plana implant and vitrectomy for treatment of neovascular glaucoma. Retina. 1995;15(5):379-387. 
9. Scott IU, Alexandrakis G, Flynn HW, et al. Combined pars planavitrectomy and glaucoma drainage implant placement for refractory glaucoma. Am J Ophthalmol. 2000;129(3):334-341.

10. Faghihi H, Hajizadeh F, Mohammadi SF, Kadkhoda A, Peyman GA, Riazi-Esfahani M. Pars plana Ahmed valve implant and vitrectomy in the management of neovascular glaucoma. Ophthalmic Surg Lasers Imaging. 2007;38(4):292-300.

11. Kolomeyer AM, Seery CW, Emami-Naeimi P, Zarbin MA, Fechtner RD, Bhagat N. Combined pars planavitrectomy and pars planaBaerveldt tube placement in eyes with neovascular glaucoma. Retina. 2015; 35(1):17-28.

12. Campagnoli TR, Kim SS, Smiddy WE, et al. Combined pars planavitrectomy and Baerveldt glaucoma implant placement for refractory glaucoma. Int J Ophthalmol. 2015;8(5):916-921.

13. Netland PA. The Ahmed glaucoma valve in neovascular glaucoma (An AOS Thesis). Trans Am Ophthalmol Soc. 2009;107:325-342.

14. Okeke CO, Miller-Ellis E, Rojas M; Trabectome Study Group. Trabectome success factors. Medicine. 2017;96(24):e7061.

15. Husain R, Clarke JC, Seah SK, Khaw PT. A review of trabeculectomy in East Asian people - the influence of race. Eye. 2005;19(3):243-252.

16. Koval MS, El Sayyad FF, Bell NP, et al. Risk factors for tube shunt exposure: a matched case-control study. J Ophthalmol. 2013;2013: 196215.

17. Wadhwa SD, Higginbotham EJ. Ethnic differences in glaucoma: prevalence, management, and outcome. Curr Opin Ophthalmol. 2005;16(2): 101-106.

18. Jampel HD, Solus JF, Tracey PA, et al. Outcomes and bleb-related complications of trabeculectomy. Ophthalmology. 2012;119(4):712-722.

19. CAT-152 Trabeculectomy Study Group, Grehn F, Holló G, et al. Factors affecting the outcome of trabeculectomy: an analysis based on combined data from two phase III studies of an antibody to transforming growth factor beta2, CAT-152. Ophthalmology. 2007;114(10): 1831-1838.

20. Broadway D, Grierson I, Hitchings R. Racial differences in the results of glaucoma filtration surgery: are racial differences in the conjunctival cell profile important? Br J Ophthalmol. 1994;78(6):466-475.

21. AGIS Investigators. The advanced glaucoma intervention study (AGIS): 9. Comparison of glaucoma outcomes in black and white patients within treatment groups. Am J Ophthalmol. 2001;132(3):311-320.

22. Five-year follow-up of the fluorouracil filtering surgery study. The Fluorouracil Filtering Surgery Study Group. Am J Ophthalmol. 1996; 121(4):349-366.

23. Chihara E, Umemoto M, Tanito M. Preservation of corneal endothelium after pars plana tube insertion of the Ahmed glaucoma valve. Jpn J Ophthalmol. 2012;56(2):119-127.

24. Adachi H, Takahashi H, Shoji T, Okazaki K, Hayashi K, Chihara E. Clinical study of the pars plana Ahmed glaucoma valve implant in refractory glaucoma patients. Nippon Ganka Gakkai Zasshi. 2008;112(6): 511-518.

25. Ueda T, Hiramatsu R, Zenno M, Koide R. Long term clinical outcomes of Baerveldt glaucoma implantation via the pars plana. Nippon GankaGakkai Zasshi. 2011;115(7):581-588.

26. Tojo N, Nakamura T, Ueda TC, Yanagisawa S, Hayashi A. Results of the Baerveldt ${ }^{\circledR}$ glaucoma implant for neovascular glaucoma patients. Nippon Ganka Gakkai Zasshi. 2017;121(2):138-145.
27. Sherwood MB, Smith MF. Prevention of early hypotony associated with Molteno implants by a new occluding stent technique. Ophthalmology. 1993;100(1):85-90.

28. Lee HY, Park JS, Choy YJ, Lee HJ. Surgical outcomes of different Ahmed glaucoma valve implantation methods between scleral graft and scleral flap. Korean J Ophthalmol. 2011;25(5):317-322.

29. Lind JT, Shute TS, Sheybani A. Patch graft materials for glaucoma tube implants. Curr Opin Ophthalmol. 2017;28(2):194-198.

30. Pakravan M, Rad SS, Yazdani S, Ghahari E, Yaseri M. Effect of early treatment with aqueous suppressants on Ahmed glaucoma valve implantation outcomes. Ophthalmology. 2014;121(9):1693-1698.

31. Shaarawy TM, Sherwood MB, Grehn F, editors. Guidelines on Design and Reporting of Glaucoma Surgical Trials. World Glaucoma Association. Amsterdam, The Netherlands: Kluger Publications; 2009.

32. Barton K, Gedde SJ, Budenz DL, Feuer WJ, Schiffman J; Ahmed Baerveldt Comparison Study Group. The Ahmed Baerveldt Comparison Study methodology, baseline patient characteristics, and intraoperative complications. Ophthalmology. 2011;118(3):435-442.

33. Christakis PG, Tsai JC, Zurakowski D, Kalenak JW, Cantor LB, Ahmed II. The Ahmed versus Baerveldt study: design, baseline patient characteristics, and intraoperative complications. Ophthalmology. 2011;118(11):2172-2179.

34. Budenz DL, Barton K, Gedde SJ, et al. Five-year treatment outcomes in the Ahmed Baerveldt comparison study. Ophthalmology. 2015 122(2):308-316.

35. Christakis PG, Kalenak JW, Tsai JC, et al. The Ahmed versus Baerveldt study: five-year treatment outcomes. Ophthalmology. 2016;123(10): 2093-2102.

36. Wang S, Gao X, Qian N. The Ahmed shunt versus the Baerveldt shunt for refractory glaucoma: a meta-analysis. BMC Ophthalmol. 2016; 16(1): $1-7$.

37. Christakis PG, Zhang D, Budenz DL, et al. Five-year pooled data analysis of the Ahmed Baerveldt comparison study and the Ahmed versus Baerveldt study. Am J Ophthalmol. 2017;176:118-126.

38. Christakis PG, Kalenak JW, Zurakowski D, et al. The Ahmed versus Baerveldt study: one-year treatment outcomes. Ophthalmology. 2011; 118(11):2180-2189.

39. Budenz DL, Barton K, Feuer WJ, et al. Treatment outcomes in the Ahmed Baerveldt comparison study after 1 year of follow-up. Ophthalmology. 2011;118(3):443-452.

40. Netland PA, Ishida K, Boyle JW. The Ahmed glaucoma valve in patients with and without neovascular glaucoma. J Glaucoma. 2010;19(9): 581-586.

41. Hwang HB, Han JW, Yim HB, Lee NY, Bin HH. Beneficial effects of adjuvant intravitreal bevacizumab injection on outcomes of Ahmed glaucoma valve implantation in patients with neovascular glaucoma: systematic literature review. J Ocul Pharmacol Ther. 2015;31(4): 198-203.

42. Zhou M, Xu X, Zhang X, Sun X. Clinical outcomes of Ahmed glaucoma valve implantation with or without intravitreal Bevacizumab pretreatment for neovascular glaucoma: a systematic review and meta-analysis. J Glaucoma. 2016;25(7):551-557.

43. Seo JW, Lee JY, Nam DH, Lee DY. Comparison of the changes in corneal endothelial cells after pars plana and anterior chamber Ahmed valve implant. J Ophthalmol. 2015;2015:486832.
Clinical Ophthalmology

\section{Publish your work in this journal}

Clinical Ophthalmology is an international, peer-reviewed journal covering all subspecialties within ophthalmology. Key topics include: Optometry; Visual science; Pharmacology and drug therapy in eye diseases; Basic Sciences; Primary and Secondary eye care; Patient Safety and Quality of Care Improvements. This journal is indexed on Submit your manuscript here: http://www.dovepress.com/clinical-ophthalmology-journal

\section{Dovepress}

PubMed Central and CAS, and is the official journal of The Society of Clinical Ophthalmology (SCO). The manuscript management system is completely online and includes a very quick and fair peer-review system, which is all easy to use. Visit http://www.dovepress.com/ testimonials.php to read real quotes from published authors. 